\title{
Angewandte
}

Supporting Information

(C) Wiley-VCH 2011

69451 Weinheim, Germany

\section{Redox-Based Probes for Protein Tyrosine Phosphatases**}

Stephen E. Leonard, Francisco J. Garcia, David S. Goodsell, and Kate S. Carroll*

ange_201007871_sm_miscellaneous_information.pdf 
Materials. Reagents and solvents were purchased from Sigma or other commercial sources and were used without further purification. DAz-1 was synthesized as previously described. ${ }^{[1]}$ YopH was expressed and purified as previously reported. ${ }^{[2]}$ Recombinant PTP1b protein was purchased from Enzo Life Sciences.

Chemical Methods. All reactions were performed under an argon atmosphere in oven-dried glassware. Analytical thin layer chromatography (TLC) was carried out using Analtech Uniplate silica gel plates and visualized using a combination of UV, potassium permanganate, and ninhydrin staining. Flash chromatography was performed using silica gel (32-63 $\mu \mathrm{M}, 60 \AA$ pore size) from Sorbent Technologies Incorporated. NMR spectra were obtained on a Varian Inova $400\left(400 \mathrm{MHz}\right.$ for ${ }^{1} \mathrm{H}$; 100 $\mathrm{MHz}$ for ${ }^{13} \mathrm{C}$ ). ${ }^{1} \mathrm{H}$ and ${ }^{13} \mathrm{C} \mathrm{NMR}$ chemical shifts are reported in parts per million (ppm) referenced to the residual solvent peak. High-resolution electrospray ionization (ESI) mass spectra were obtained with a Micromass AutoSpec Ultima Magnetic sector mass spectrometer at the University of Michigan Mass Spectrometry Laboratory. Low-resolution ESI mass spectra were obtained with a Micromass LCT Time-of-Flight mass spectrometer. Microwave reactions were performed in a Biotage Initiator Microwave Synthesizer.<smiles></smiles>

Amino-N-(3-azidopropyl)benzamide (9): A 2-5 $\mathrm{mL}$ process vial flushed with argon was charged with a solution of 4-aminobenzoic acid (100 mg, $0.73 \mathrm{mmol})$, EDC (280 mg, $1.46 \mathrm{mmol})$ and DMAP (179 mg, $1.46 \mathrm{mmol})$ in dry DMF (5 mL). Subsequently 3-azidopropylamine (146 mg, $1.46 \mathrm{mmol}$ ) and TEA $(0.204 \mathrm{~mL}, 1.46 \mathrm{mmol})$ were added to the solution. The vial was sealed, placed into the cavity of 
the microwave reactor and irradiated at $120^{\circ} \mathrm{C}$ for $0.5 \mathrm{~h}$. The DMF was removed in vacuo and the resulting oil was extracted with $\mathrm{DCM} / \mathrm{H}_{2} \mathrm{O}(3 \times 15 \mathrm{~mL})$. The organic phases were combined, dried over $\mathrm{Na}_{2} \mathrm{SO}_{4}$, filtered, and concentrated. Flash column chromatography was used for purification (EtOAc/Hexanes 6:4) to yield an oil, 4-amino-N-(3-azidopropyl)benzamide (9) $(80 \mathrm{mg}, 50 \%) .{ }^{1} \mathrm{H}$ $\operatorname{NMR}\left(400 \mathrm{MHz}, \mathrm{CDCl}_{3}\right) \delta 7.57(\mathrm{~d}, \mathrm{~J}=8.5 \mathrm{~Hz}, 2 \mathrm{H}), 6.80(\mathrm{~s}, 1 \mathrm{H}), 6.56(\mathrm{~d}, \mathrm{~J}=8 \mathrm{~Hz}, 2 \mathrm{H}), 4.14(\mathrm{~s}, 2 \mathrm{H})$, $3.431-3.383(\mathrm{~m}, 2 \mathrm{H}), 3.30(\mathrm{t}, \mathrm{J}=6.7 \mathrm{~Hz}, 2 \mathrm{H}), 1.824-1.757(\mathrm{~m}, 2 \mathrm{H}) .{ }^{13} \mathrm{C} \mathrm{NMR}\left(100 \mathrm{MHz}, \mathrm{CDCl}_{3}\right) \delta$ 167.7, 149.9, 128.6, 123.0, 49.3, 37.4, 28.8. ESIHRMS calcd. for $\mathrm{C}_{10} \mathrm{H}_{13} \mathrm{~N}_{5} \mathrm{O}(\mathrm{M}+\mathrm{Na}) 242.11$, found 242.1024.<smiles>COC1=CC(=O)CC(C(=O)Nc2ccc(C(=O)NCCCN)cc2)C1</smiles>

N-(3-azidopropyl)-4-(3-methoxy-5-oxocyclohex-3-enecarboxamido)benzamide (10): A 2-5 mL process vial flushed with argon was charged with 4-amino-N-(3-azidopropyl)benzamide (9) (363 mg, $1.66 \mathrm{mmol})$ and TEA $(0.28 \mathrm{~mL}, 1.99 \mathrm{mmol})$ in dry DMF $(2.5 \mathrm{~mL})$. To this was added a solution of 3methoxy-5-oxocyclohex-3-enecarboxylic acid (339 mg, $1.99 \mathrm{mmol})$, EDC (382 mg, $1.99 \mathrm{mmol})$, and DMAP (243 mg, $1.99 \mathrm{mmol})$ in dry DMF $(2.5 \mathrm{~mL})$. The vial was sealed, placed into the cavity of the microwave reactor and irradiated at $120^{\circ} \mathrm{C}$ for $0.5 \mathrm{~h}$. The DMF was removed in vacuo and the resulting oil was extracted with $\mathrm{DCM} / \mathrm{H}_{2} \mathrm{O}(3 \times 15 \mathrm{~mL})$. The organic phases were combined, dried over $\mathrm{Na}_{2} \mathrm{SO}_{4}$, filtered, and concentrated. Purification was completed with flash column chromatography (EtOAc/Hexanes 1:1 to EtOAc) to yield N-(3-azidopropyl)-4-(3-methoxy-5oxocyclohex-3-enecarboxamido)benzamide (10) $(129 \mathrm{mg}, 21 \%) .{ }^{1} \mathrm{H}$ NMR $\left(400 \mathrm{MHz}, \mathrm{CDCl}_{3}\right) \delta 8.95$ (s, 1H), $7.68(\mathrm{~d}, \mathrm{~J}=8.4 \mathrm{~Hz}, 2 \mathrm{H}), 7.62(\mathrm{~d}, \mathrm{~J}=8.3 \mathrm{~Hz}, 2 \mathrm{H}), 6.73(\mathrm{~s}, 1 \mathrm{H}), 5.37(\mathrm{~s}, 1 \mathrm{H}), 3.70(\mathrm{~s}, 3 \mathrm{H}), 3.55$ $-3.49(\mathrm{~m}, 2 \mathrm{H}), 3.42(\mathrm{t}, \mathrm{J}=6.5 \mathrm{~Hz}, 2 \mathrm{H}), 3.14-3.10(\mathrm{~m}, 1 \mathrm{H}), 2.95-2.88(\mathrm{~m}, 2 \mathrm{H}), 2.69-2.52(\mathrm{~m}, 2 \mathrm{H})$, 
$1.92-1.86(\mathrm{~m}, 2 \mathrm{H}) .{ }^{13} \mathrm{C} \mathrm{NMR}\left(100 \mathrm{MHz}, \mathrm{CD}_{3} \mathrm{OD}\right) \delta 198.8,178.9,168.2,141.5,129.4,127.7,118.9$, 100.8, 55.5, 48.0, 40.8, 38.7, 37.0, 36.9, 30.9, 28.4. ESIHRMS calcd. for $\mathrm{C}_{18} \mathrm{H}_{21} \mathrm{~N}_{5} \mathrm{O}_{4}(\mathrm{M}+\mathrm{Na})$ 394.16, found 394.1495 .<smiles>NCCCNC(=O)c1ccc(NC(=O)C2CC(=O)CC(=O)C2)cc1</smiles>

N-(3-azidopropyl)-4-(3,5-dioxocyclohex-3-enecarboxamido)benzamide (3): N-(3-azidopropyl)-4(3-methoxy-5-oxocyclohex-3-enecarboxamido)benzamide (10) $(129 \mathrm{mg}, .348 \mathrm{mmol})$ was added to a solution of $\mathrm{ACN} / \mathrm{H}_{2} \mathrm{O}(1: 1 \mathrm{v} / \mathrm{v}, 10 \mathrm{~mL})$ with $10 \mathrm{~mol} \% \mathrm{CAN}(19 \mathrm{mg}, .0348 \mathrm{mmol})$ and refluxed at 95 ${ }^{\circ} \mathrm{C}$ for $3 \mathrm{~h}$. The reaction was cooled and concentrated. Flash column chromatography was used for purification (EtOAc to EtOAc/MeOH 9:1) to yield a yellow solid (3) (123 mg, 99\%). ${ }^{1} \mathrm{H}$ NMR (400 MHz, DMSO-d $\left.{ }_{6}\right) \delta 10.22(\mathrm{~s}, 1 \mathrm{H}), 8.41(\mathrm{t}, \mathrm{J}=5.4 \mathrm{~Hz}, 1 \mathrm{H}), 7.81(\mathrm{~d}, \mathrm{~J}=8.7 \mathrm{~Hz}, 2 \mathrm{H}), 7.66(\mathrm{~d}, \mathrm{~J}=8.7 \mathrm{~Hz}$, 2H), $5.24(\mathrm{~s}, 1 \mathrm{H}), 3.40(\mathrm{t}, \mathrm{J}=6.7 \mathrm{~Hz}, 2 \mathrm{H}), 3.32-3.28(\mathrm{~m}, 2 \mathrm{H}), 3.19-3.10(\mathrm{~m}, 1 \mathrm{H}), 2.57-2.52(\mathrm{~m}$, 2H), $2.50-2.42(\mathrm{~m}, 2 \mathrm{H}), 1.80-1.73(\mathrm{~m}, 2 \mathrm{H}) .{ }^{13} \mathrm{C}$ NMR (100 MHz, DMSO-d 6 ) $\delta$ 171.9, 166.1, 141.9, 129.4, 128.4, 118.7, 103.7, 48.9, 39.9, 28.8. ESIHRMS calcd. for $\mathrm{C}_{17} \mathrm{H}_{19} \mathrm{~N}_{5} \mathrm{O}_{4}(\mathrm{M}+\mathrm{Na}) 380.14$, found 380.1325 .<smiles>O=C(NCc1ccc(C(=O)O)cc1)OCC1c2ccccc2-c2ccccc21</smiles>

4-((((9H-fluoren-9-yl)methoxy)carbonyl)amino)methyl)benzoic acid (11): To a solution of $\mathrm{NaHCO}_{3}(10 \% \mathrm{w} / \mathrm{v}, 10 \mathrm{~mL})$ was added 4-(aminomethyl)benzoic acid $(300 \mathrm{mg}, 1.99 \mathrm{mmol})$. FMOCOSU ( $805 \mathrm{mg}, 2.98 \mathrm{mmol})$ was solubilized in THF $(5 \mathrm{~mL})$ and added drop wise to the reaction with 
vigorous stirring. The mixture was stirred at $\mathrm{RT}$ overnight. $1 \mathrm{~N} \mathrm{HCl}$ was added to acidify the solution. The aqueous phase was then extracted with EtOAc $(3 \times 15 \mathrm{~mL})$, the organic phases were combined, dried over $\mathrm{Na}_{2} \mathrm{SO}_{4}$, filtered, and concentrated. Purification was carried out by flash column chromatography (EtOAc/Hexanes 6:4 to EtOAc) giving the final product (11) $(342 \mathrm{mg}, 46 \%) .{ }^{1} \mathrm{H}$ NMR (400 MHz, DMSO-d $)_{6} \delta 7.95-7.91(\mathrm{~m}, 2 \mathrm{H}), 7.89(\mathrm{~d}, \mathrm{~J}=6.9 \mathrm{~Hz}, 2 \mathrm{H}), 7.70(\mathrm{~d}, \mathrm{~J}=7.4 \mathrm{~Hz}, 2 \mathrm{H})$, $7.42(\mathrm{t}, \mathrm{J}=7.4 \mathrm{~Hz}, 2 \mathrm{H}), 7.34(\mathrm{~d}, \mathrm{~J}=3.5 \mathrm{~Hz}, 2 \mathrm{H}) 7.32(\mathrm{~d}, \mathrm{~J}=4.8 \mathrm{~Hz}, 2 \mathrm{H}), 4.39$ (d, J = 6.7 Hz, 2H), 4.24 $(\mathrm{t}, \mathrm{J}=7.7 \mathrm{~Hz}, 2 \mathrm{H}), 2.59$ ( s, 1H). ${ }^{13} \mathrm{C}$ NMR (100 MHz, DMSO-d 6 ) $\delta 173.2,167.6,156.8,145.3,144.2$, $141.2,129.7,128.0,127.4,125.5,120.5,65.7,47.2,43.9,25.6$. ESIHRMS calcd. for $\mathrm{C}_{23} \mathrm{H}_{19} \mathrm{NO}_{4}(\mathrm{M}+$ Na) 396.1312, found 396.1212 .

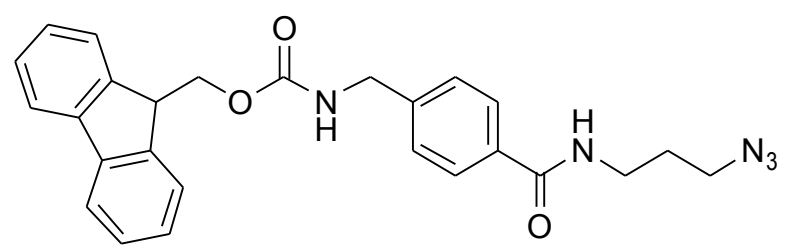

(9H-fluoren-9-yl)methyl 4-((3-azidopropyl)carbamoyl)benzylcarbamate (12): To an oven-dried flask, flushed with argon, was added a solution of 4-((()(9H-fluoren-9yl)methoxy)carbonyl)amino)methyl)benzoic acid (11) $(318 \mathrm{mg}, .853 \mathrm{mmol}$ ) in anhydrous DMF (5 mL). TFA-Pfp was added $(0.18 \mathrm{~mL}, 1.02 \mathrm{mmol})$ as well as TEA $(0.143 \mathrm{~mL}, 1.02 \mathrm{mmol})$. The mixture was stirred at RT for $2 \mathrm{~h}$ before adding 3-azidopropylamine (103 mg, $1.02 \mathrm{mmol})$ and TEA (0.14 mL, $1.02 \mathrm{mmol}$ ). The reaction mixture was then left stirring overnight at RT. DMF was removed in vacuo and the resulting oil was extracted with $\mathrm{DCM} / \mathrm{H}_{2} \mathrm{O}(3 \times 15 \mathrm{~mL})$. The organic phases were combined, dried with $\mathrm{Na}_{2} \mathrm{SO}_{4}$, filtered, and concentrated. Purification was carried out by flash column chromatography (EtOAc/Hexanes 2:8 to 6:4) yielding the product (12) (243 $\mathrm{mg}, 63 \%) .{ }^{1} \mathrm{H}$ NMR (400 MHz, DMSO-d $)) \delta 8.48(\mathrm{t}, \mathrm{J}=5.4 \mathrm{~Hz}, 1 \mathrm{H}), 7.89(\mathrm{~d}, \mathrm{~J}=7.4 \mathrm{~Hz}, 2 \mathrm{H}), 7.79(\mathrm{~d}, \mathrm{~J}=8.1 \mathrm{~Hz}, 2 \mathrm{H}), 7.70(\mathrm{~d}, \mathrm{~J}$ $=7.4 \mathrm{~Hz}, 2 \mathrm{H}), 7.42(\mathrm{t}, \mathrm{J}=7.4 \mathrm{~Hz}, 2 \mathrm{H}), 7.33(\mathrm{t}, \mathrm{J}=7.4 \mathrm{~Hz}, 2 \mathrm{H}), 7.29(\mathrm{~d}, \mathrm{~J}=8.1 \mathrm{~Hz}, 2 \mathrm{H}), 4.39-4.35$ $(\mathrm{m}, 2 \mathrm{H}), 4.24(\mathrm{t}, \mathrm{J}=6.1 \mathrm{~Hz}, 2 \mathrm{H}), 3.41(\mathrm{t}, \mathrm{J}=6.7 \mathrm{~Hz}, 2 \mathrm{H}), 3.33-3.30(\mathrm{~m}, 2 \mathrm{H}), 1.82-1.74(\mathrm{~m}, 2 \mathrm{H}) .{ }^{13} \mathrm{C}$ 
NMR (100 MHz, DMSO-d 6 ) $\delta 166.5,156.8,144.2,143.3,141.1,133.4,128.0,127.6,127.4,127.1$, 125.5, 120.5, 65.7, 48.9, 47.2, 37.04, 28.8. ESIHRMS calcd. for $\mathrm{C}_{26} \mathrm{H}_{25} \mathrm{~N}_{5} \mathrm{O}_{3}(\mathrm{M}+\mathrm{Na}) 478.20$, found 478.1855 .<smiles>N#CCCCNC(=O)c1ccc(CN)cc1</smiles>

4-(aminomethyl)-N-(3-azidopropyl)benzamide (13): In a round bottom flask, (9H-fluoren-9yl)methyl 4-((3-azidopropyl)carbamoyl)benzylcarbamate (12) (119 mg, $0.261 \mathrm{mmol})$ was added to a solution of ethanolamine in DCM $(1: 1 \mathrm{v} / \mathrm{v}, 5 \mathrm{~mL})$ and stirred for $3 \mathrm{~h}$. The reaction mixture was washed with saturated $\mathrm{NaHCO}_{3}$ and extracted with DCM $(3 \times 15 \mathrm{~mL})$. The organic phases were combined, dried over $\mathrm{Na}_{2} \mathrm{SO}_{4}$, filtered, and concentrated. Flash column chromatography was used for purification (EtOAc/Hexanes 8:2 to EtOAc/MeOH 9:1) to yield 4-(aminomethyl)-N-(3-azidopropyl)benzamide (13) (40 mg, 66\%). ${ }^{1} \mathrm{H}$ NMR (400 MHz, $\left.\mathrm{CDCl}_{3}\right) \delta 7.73(\mathrm{~d}, \mathrm{~J}=8.0 \mathrm{~Hz}, 2 \mathrm{H}), 7.37(\mathrm{~d}, \mathrm{~J}=8.0 \mathrm{~Hz}, 2 \mathrm{H}), 6.50$ $(\mathrm{s}, 1 \mathrm{H}), 3.92(\mathrm{~s}, 2 \mathrm{H}), 3.56-3.52(\mathrm{~m}, 2 \mathrm{H}), 3.46-3.42(\mathrm{~m}, 2 \mathrm{H}), 2.12(\mathrm{~s}, 2 \mathrm{H}), 1.92-1.87(\mathrm{~m}, 2 \mathrm{H}) .{ }^{13} \mathrm{C}$ NMR $\left(100 \mathrm{MHz}, \mathrm{CDCl}_{3}\right) \delta 167.4,146.4,132.9,128.0,126.9,49.5,45.8,37.7,28.7$. ESIHRMS calcd. for $\mathrm{C}_{26} \mathrm{H}_{25} \mathrm{~N}_{5} \mathrm{O}_{3}(\mathrm{M}+\mathrm{H}) 234.13$, found 234.1355.<smiles>COC1=CC(=O)CC(C(=O)NCc2ccc(C(=O)NCCCN)cc2)C1</smiles>

N-(3-azidopropyl)-4-((3-methoxy-5-oxocyclohex-3-enecarboxamido)methyl)benzamide (14): In an oven-dried round bottom flask, EDC (50 mg, .258 mmol) and DMAP (32 mg, .258 mmol) were added to a solution of 3-methoxy-5-oxocyclohex-3-enecarboxylic acid (44 mg, .2575 mmol) in anhydrous 
DMF (2.5 mL) under argon. To this was added 4-(aminomethyl)-N-(3-azidopropyl)benzamide (13) (40 $\mathrm{mg}, 0.172 \mathrm{mmol})$ in anhydrous DMF $(2.5 \mathrm{~mL})$ and TEA $(0.04 \mathrm{~mL}, 0.258 \mathrm{mmol})$ and the reaction was stirred overnight at $45^{\circ} \mathrm{C}$. The DMF was removed in vacuo and the resulting oil was extracted using $\mathrm{DCM} / \mathrm{H}_{2} \mathrm{O}(3 \times 15 \mathrm{~mL})$. The organic phases were combined, dried with $\mathrm{Na}_{2} \mathrm{SO}_{4}$, filtered, and concentrated. Flash column chromatography was used to purify the product (EtOAc/Hexanes 3:7 to EtOAc/MeOH 9:1) yielding N-(3-azidopropyl)-4-((3-methoxy-5-oxocyclohex-3enecarboxamido)methyl)benzamide (14) $(34 \mathrm{mg}, 52 \%) .{ }^{1} \mathrm{H} \mathrm{NMR}\left(400 \mathrm{MHz}, \mathrm{CDCl}_{3}\right) \delta 7.66(\mathrm{~d}, \mathrm{~J}=8.3$ $\mathrm{Hz}, 2 \mathrm{H}), 7.25(\mathrm{~d}, \mathrm{~J}=7.3 \mathrm{~Hz}, 2 \mathrm{H}), 5.35(\mathrm{~s}, 1 \mathrm{H}), 4.46(\mathrm{~m}, 2 \mathrm{H}), 3.70(\mathrm{~s}, 3 \mathrm{H}), 3.56-3.51(\mathrm{~m}, 2 \mathrm{H}), 3.44(\mathrm{t}$, $\mathrm{J}=6.5 \mathrm{~Hz}, 2 \mathrm{H}), 2.95-2.82(\mathrm{~m}, 1 \mathrm{H}), 2.79-2.72(\mathrm{~m}, 2 \mathrm{H}), 2.48-2.41(\mathrm{~m}, 2 \mathrm{H}), 1.92-1.87(\mathrm{~m}, 2 \mathrm{H})$.

${ }^{13} \mathrm{C}$ NMR $\left(100 \mathrm{MHz}, \mathrm{CDCl}_{3}\right) \delta 197.6,177.5,172.6,167.8,141.8,133.4,127.2,101.4,56.0,49.3,42.8$, 40.3, 37.6, 31.4, 29.6, 28.65. ESIHRMS calcd. for $\mathrm{C}_{19} \mathrm{H}_{23} \mathrm{~N}_{5} \mathrm{O}_{4}(\mathrm{M}+\mathrm{Na}) 408.18$, found 408.1648.

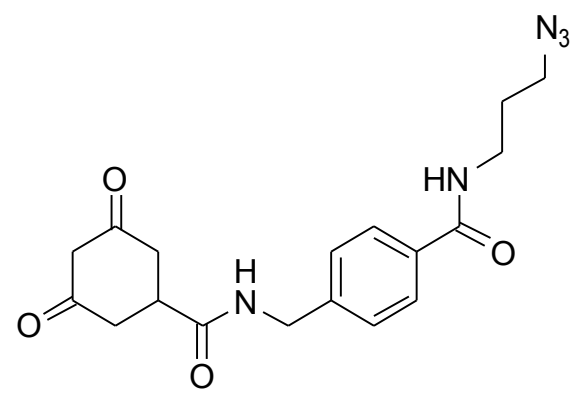

N-(3-azidopropyl)-4-((3,5-dioxocyclohex-3-enecarboxamido)methyl)benzamide (4): In a round bottom flask, N-(3-azidopropyl)-4-((3-methoxy-5-oxocyclohex-3-enecarboxamido)methyl)benzamide (14) $(100 \mathrm{mg}, 0.260 \mathrm{mmol})$ was added to a solution of $\mathrm{ACN} / \mathrm{H}_{2} \mathrm{O}(1: 1 \mathrm{v} / \mathrm{v}, 5 \mathrm{~mL})$ with $10 \mathrm{~mol} \% \mathrm{CAN}$ (14 mg, $0.026 \mathrm{mmol}$ ) and refluxed at $95{ }^{\circ} \mathrm{C}$ for $3 \mathrm{~h}$. Solvent was removed in vacuo. Flash column chromatography was used to purify the product (EtOAc to EtOAc/MeOH 9:1) yielding (4) (89 mg, 92\%). ${ }^{1} \mathrm{H}$ NMR (400 MHz, DMSO-d 6 ) $\delta 8.53(\mathrm{t}, \mathrm{J}=5.7 \mathrm{~Hz}, 1 \mathrm{H}), 8.48(\mathrm{t}, \mathrm{J}=5.5 \mathrm{~Hz}, 1 \mathrm{H}), 7.79(\mathrm{~d}, \mathrm{~J}=$ $8.2 \mathrm{~Hz}, 2 \mathrm{H}), 7.30(\mathrm{~d}, \mathrm{~J}=8.1 \mathrm{~Hz}, 2 \mathrm{H}), 5.20(\mathrm{~s}, 1 \mathrm{H}), 4.32(\mathrm{~d}, \mathrm{~J}=5.8 \mathrm{~Hz}, 2 \mathrm{H}), 3.40(\mathrm{t}, \mathrm{J}=6.7 \mathrm{~Hz}, 2 \mathrm{H})$, $3.34-3.29(\mathrm{~m}, 2 \mathrm{H}), 3.01-2.97(\mathrm{~m}, 1 \mathrm{H}), 2.46(\mathrm{~d}, \mathrm{~J}=10.9 \mathrm{~Hz}, 2 \mathrm{H}), 2.38-2.32(\mathrm{~m}, 2 \mathrm{H}), 1.82-1.72$ 
(m, 2H). ${ }^{13} \mathrm{C}$ NMR (100 MHz, DMSO-d 6 ) $\delta$ 172.7, 166.5, 143.0, 133.4, 127.6, 127.1, 103.7, 48.9, 42.2, 37.0, 28.8. ESIHRMS calcd. for $\mathrm{C}_{18} \mathrm{H}_{21} \mathrm{~N}_{5} \mathrm{O}_{4}(\mathrm{M}+\mathrm{Na}) 394.16$, found 394.1491 .<smiles>N#CCCNC(=O)c1ccc2cc(N)ccc2c1</smiles>

\section{6-amino-N-(3-azidopropyl)-2-naphthamide (15):}

A 2-5 $\mathrm{mL}$ process vial flushed with argon was charged with a solution of 6-amino-2-naphthoic acid (50 mg, $0.27 \mathrm{mmol})$, EDC (58 $\mathrm{mg}, 0.30 \mathrm{mmol})$ and DMAP (52 $\mathrm{mg}, 0.30 \mathrm{mmol})$ in dry DMF $(3 \mathrm{~mL})$. Subsequently 3-azidopropylamine $(54 \mathrm{mg}, 0.54 \mathrm{mmol})$ and TEA $(0.080 \mathrm{~mL}, 0.54 \mathrm{mmol})$ were also added to the solution. The vial was sealed, placed into the cavity of the microwave reactor and irradiated at $120^{\circ} \mathrm{C}$ for $0.5 \mathrm{~h}$. The DMF was removed in vacuo and the resulting oil was extracted with $\mathrm{DCM} / \mathrm{H}_{2} \mathrm{O}(3 \times 15 \mathrm{~mL})$. Flash column chromatography was used for purification (EtOAc/Hexanes 1:1) to yield an orange solid (15) $(35 \mathrm{mg}, 48 \%) .{ }^{1} \mathrm{H}$ NMR $\left(400 \mathrm{MHz}, \mathrm{CD}_{3} \mathrm{OD}\right): \delta 8.16(\mathrm{~s}, 1 \mathrm{H}), 7.71$ (d, $J=8.8,1 \mathrm{H}), 7.68(\mathrm{~d}, J=9.2,1 \mathrm{H}), 7.75(\mathrm{~d}, J=8.8,1 \mathrm{H}), 7.03(\mathrm{~d}, J=8.4,1 \mathrm{H}), 6.96(\mathrm{~d}, J=1.6,1 \mathrm{H}), 3.47(\mathrm{t}$, $J=6.8,2 \mathrm{H}), 3.40(\mathrm{t}, J=6.8,2 \mathrm{H}), 1.88(\mathrm{q}, J=6.4,2 \mathrm{H}){ }^{13} \mathrm{C} \mathrm{NMR}\left(100 \mathrm{MHz}, \mathrm{CD}_{3} \mathrm{OD}\right): \delta 169.36,147.78$, $137.02,129.75,127.42,126.85,126.29,125.31,123.58,118.9,106.93,48.84,36.99,28.50$. ESIHRMS calcd. for $\mathrm{C}_{11} \mathrm{H}_{17} \mathrm{~N}_{3} \mathrm{O}_{2}(\mathrm{M}+\mathrm{Na})$ 292.1174, found 292.1175.<smiles>COC1=CC(=O)CC(C(=O)Nc2ccc3cc(C(=O)NCCCN)ccc3c2)C1</smiles>

N-(3-azidopropyl)-6-(3-methoxy-5-oxocyclohex-3-enecarboxamido)-2-naphthamide (16):

A 2-5 mL process vial flushed with argon was charged with a solution of 3-methoxy-5-oxocyclohex-3- 
enecarboxylic acid (22 mg, $0.13 \mathrm{mmol}), \mathrm{EDC}(27 \mathrm{mg}, 0.14 \mathrm{mmol})$ and DMAP (25 mg, $0.14 \mathrm{mmol})$ in dry DMF (3 mL). 6-amino-N-(3-azidopropyl)-2-naphthamide (15) (35 mg, $0.13 \mathrm{mmol})$ and TEA (0.02 $\mathrm{mL}, 0.13 \mathrm{mmol})$ in dry DMF $(2 \mathrm{~mL})$ were then added to the solution. The vial was sealed, placed into the cavity of the microwave reactor and irradiated at $120^{\circ} \mathrm{C}$ for $0.5 \mathrm{~h}$. The DMF was removed in vacuo and the resulting oil was extracted with $\mathrm{DCM} / \mathrm{H}_{2} \mathrm{O}(3 \times 15 \mathrm{~mL})$. The organic phases were combined, dried over $\mathrm{Na}_{2} \mathrm{SO}_{4}$, filtered, and concentrated. Flash column chromatography was used for purification (EtOAc/Hexanes 1:1 to EtOAc) to yield an orange solid (16) (33 mg, 62\%). ${ }^{1} \mathrm{H}$ NMR $\left(400 \mathrm{MHz}, \mathrm{DMSO}-\mathrm{d}_{6}\right): \delta 8.60(\mathrm{t}, J=4.8,1 \mathrm{H}), 8.33(\mathrm{~d}, J=9.2,2 \mathrm{H}), 8.16(\mathrm{~d}, J=6.8,1 \mathrm{H}), 7.93(\mathrm{~d}, J=8.8$, 1H), $7.84(\mathrm{~s}, 1 \mathrm{H}), 7.60(\mathrm{~d}, J=7.2,1 \mathrm{H}), 6.90(\mathrm{~d}, J=6.4,1 \mathrm{H}), 5.35(\mathrm{~s}, 1 \mathrm{H}), 3.68(\mathrm{~s}, 3 \mathrm{H}), 3.41(\mathrm{t}, J=6.8$, $2 \mathrm{H}), 3.18(\mathrm{t}, J=2.4,2 \mathrm{H}), 3.13(\mathrm{~s}, 2 \mathrm{H}), 3.12-2.56(\mathrm{~m}, 3 \mathrm{H}), 1.78(\mathrm{q}, J=6.8,2 \mathrm{H}) .{ }^{13} \mathrm{C} \mathrm{NMR}(100 \mathrm{MHz}$, DMSO-d $)_{6}: \delta 196.64,176.97,171.89,167.43,166.87,138.42,135.13,130.94,130.00,129.18,127.74$, $127.56,125.10,120.97,115.31,56.51,49.00,40.58,37.15,31.28,28.88$. ESIHRMS calcd. for $\mathrm{C}_{22} \mathrm{H}_{23} \mathrm{~N}_{5} \mathrm{O}_{4}(\mathrm{M}+\mathrm{Na}) 444.1458$, found 444.1649 .

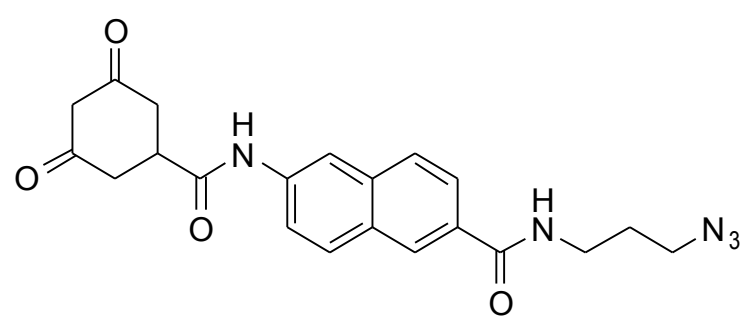

\section{N-(3-azidopropyl)-6-(3,5-dioxocyclohex-3-enecarboxamido)-2-naphthamide (5):}

In a round bottom flask, (16) $(33 \mathrm{mg}, 0.08 \mathrm{mmol})$ was added to a solution of $\mathrm{ACN} / \mathrm{H}_{2} \mathrm{O}(1: 1 \mathrm{v} / \mathrm{v}, 5 \mathrm{~mL})$ with $10 \% \mathrm{CAN}(4.4 \mathrm{mg}, 0.008 \mathrm{mmol})$ and refluxed at $95{ }^{\circ} \mathrm{C}$ for $3 \mathrm{~h}$. The reaction was cooled and concentrated. Flash column chromatography was used for purification (EtOAc to EtOAc/MeOH 9:1) to yield an orange solid (5) $(30 \mathrm{mg}, 92 \%) .{ }^{1} \mathrm{H}$ NMR (400MHz, DMSO-d 6$): \delta 8.29(\mathrm{~s}, 2 \mathrm{H}), 7.92(\mathrm{~d}$, $J=8.8,1 \mathrm{H}), 7.84(\mathrm{~s}, 2 \mathrm{H}), 7.63(\mathrm{~d}, J=8.8,1 \mathrm{H}), 5.10(\mathrm{~s}, 1 \mathrm{H}), 3.49(\mathrm{t}, J=4.4,2 \mathrm{H}), 3.43(\mathrm{t}, J=6.8,2 \mathrm{H}), 2.75-$ $2.53(\mathrm{~m}, 4 \mathrm{H}), 1.9(\mathrm{q}, J=7.2,2 \mathrm{H}), 1.56(\mathrm{t}, J=7.2,1 \mathrm{H})$. ESIHRMS calcd. for C21H21N5O4 $(\mathrm{M}+\mathrm{Na})$ 


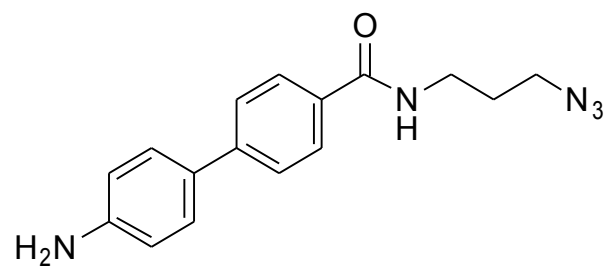

\section{4'-amino-N-(3-azidopropyl)-[1,1'-biphenyl]-4-carboxamide (17):}

A 2-5 mL process vial flushed with argon was charged with a solution of 4'-amino-[1,1'-biphenyl]-4carboxylic acid (125 mg, $0.587 \mathrm{mmol})$, EDC (122 mg, $0.646 \mathrm{mmol})$ and DMAP (110 mg, $0.30 \mathrm{mmol})$ in dry DMF (3 mL). Subsequently 3-azidopropylamine $(88 \mathrm{mg}, 0.88 \mathrm{mmol})$ and TEA $(0.13 \mathrm{~mL}, 0.88$ mmol) were also added to the solution. The vial was sealed, placed into the cavity of the microwave reactor and irradiated at $120^{\circ} \mathrm{C}$ for $0.5 \mathrm{~h}$. The DMF was removed in vacuo and the resulting oil was extracted with DCM and 10\% (v/v) sodium bicarbonate $(3 \times 15 \mathrm{~mL})$. Flash column chromatography was used for purification (EtOAc/Hexanes 4:6) to yield a white solid (17) (39 mg, 23\%). ${ }^{1} \mathrm{H}$ NMR (400 MHz, CD 3 OD) $\delta 7.87-7.79(\mathrm{~m}, 2 \mathrm{H}), 7.73(\mathrm{dd}, J=5.8,3.3 \mathrm{~Hz}, 1 \mathrm{H}), 7.67-7.60(\mathrm{~m}, 2 \mathrm{H}), 7.45(\mathrm{~d}$, $J=8.5 \mathrm{~Hz}, 2 \mathrm{H}), 6.80(\mathrm{~d}, J=8.5 \mathrm{~Hz}, 2 \mathrm{H}), 3.48(\mathrm{t}, J=6.8 \mathrm{~Hz}, 2 \mathrm{H}), 3.43(\mathrm{t}, J=6.7 \mathrm{~Hz}, 2 \mathrm{H}), 1.90(\mathrm{dd}, J$ $=13.6,6.9 \mathrm{~Hz}, 2 \mathrm{H}) .{ }^{13} \mathrm{C} \mathrm{NMR}\left(100 \mathrm{MHz}, \mathrm{CDCl}_{3}\right) \delta 167.42,146.56,144.27,131.80,129.96,128.08$, 127.29, 126.22, 115.32, 49.59, 37.75, , 28.81. ESILRMS calcd. for $\mathrm{C}_{16} \mathrm{H}_{17} \mathrm{~N}_{5} \mathrm{O}(\mathrm{M}+\mathrm{H})$ 296, found 296.<smiles>COC1=CC(=O)CC(C(=O)Nc2ccc(-c3ccc(C(=O)NCCCN)cc3)cc2)C1</smiles> 
carboxamide (18):

A 2-5 mL process vial flushed with argon was charged with a solution of 3-methoxy-5-oxocyclohex-3enecarboxylic acid (23.8 mg, $0.14 \mathrm{mmol})$, EDC (26.8 mg, $0.14 \mathrm{mmol})$ and DMAP (25 mg, $0.14 \mathrm{mmol})$ in dry DMF (3 mL). 4'-amino-N-(3-azidopropyl)-[1,1'-biphenyl]-4-carboxamide (17) (39 mg, 0.13 mmol) and TEA $(0.02 \mathrm{~mL}, 0.13 \mathrm{mmol})$ in dry DMF $(2 \mathrm{~mL})$ were also added to the solution. The vial was sealed, placed into the cavity of the microwave reactor and irradiated at $120{ }^{\circ} \mathrm{C}$ for $0.5 \mathrm{~h}$. The DMF was removed in vacuo and the resulting oil was extracted with $\mathrm{DCM} / \mathrm{H}_{2} \mathrm{O}(3 \times 15 \mathrm{~mL})$. The organic phases were combined, dried over $\mathrm{Na}_{2} \mathrm{SO}_{4}$, filtered, and concentrated. Flash column chromatography was used for purification (EtOAc/Hexanes 6:4 to EtOAc) to yield a brown solid (18) (12 mg, 21\%). ${ }^{1} \mathrm{H}$ NMR (400 MHz, $\left.\mathrm{CDCl}_{3}\right) \delta 7.81(\mathrm{~d}, J=8.4 \mathrm{~Hz}, 2 \mathrm{H}), 7.61(\mathrm{~d}, J=8.4 \mathrm{~Hz}, 6 \mathrm{H}), 7.58$ $(\mathrm{s}, 1 \mathrm{H}), 7.55(\mathrm{~d}, J=8.2 \mathrm{~Hz}, 1 \mathrm{H}), 6.40(\mathrm{~s}, 1 \mathrm{H}), 5.42(\mathrm{~s}, 1 \mathrm{H}), 3.71(\mathrm{~d}, J=12.8 \mathrm{~Hz}, 3 \mathrm{H}), 3.65-3.56(\mathrm{~m}$, 2H), $3.56-3.41(\mathrm{~m}, 2 \mathrm{H}), 3.08-2.85(\mathrm{~m}, 2 \mathrm{H}), 2.77-2.50(\mathrm{~m}, 3 \mathrm{H}), 1.98-1.79(\mathrm{~m}, 2 \mathrm{H})$. ESIHRMS calcd. for $\mathrm{C}_{24} \mathrm{H}_{25} \mathrm{~N}_{5} \mathrm{O}_{4}(\mathrm{M}+\mathrm{Na}) 470.1804$, found 470.1790 .<smiles>N#CCCNC(=O)c1ccc(-c2ccc(NC(=O)C3CC(=O)CC(=O)C3)cc2)cc1</smiles>

N-(3-azidopropyl)-4' -(3,5-dioxocyclohex-3-enecarboxamido)-[1,1'-biphenyl]-4-carboxamide (6): In a round bottom flask, $(\mathbf{1 8})(12 \mathrm{mg}, 0.027 \mathrm{mmol})$ was added to a solution of $\mathrm{ACN} / \mathrm{H}_{2} \mathrm{O}(1: 1 \mathrm{v} / \mathrm{v}, 5$ $\mathrm{mL}$ ) with $10 \% \mathrm{CAN}(1.6 \mathrm{mg}, 0.003 \mathrm{mmol})$ and refluxed at $95{ }^{\circ} \mathrm{C}$ for $3 \mathrm{~h}$. The reaction was cooled and concentrated. Flash column chromatography was used for purification (EtOAc to EtOAc/MeOH 9:1) to yield a yellow solid (6) $(10 \mathrm{mg}, 85 \%) .{ }^{1} \mathrm{H}$ NMR (400 MHz, $\left.\mathrm{CD}_{3} \mathrm{OD}\right) \delta 8.58(\mathrm{~s}, 1 \mathrm{H}), 7.89(\mathrm{~d}, J=8.6$ $\mathrm{Hz}, 2 \mathrm{H}), 7.69(\mathrm{dt}, J=17.3,8.8 \mathrm{~Hz}, 6 \mathrm{H}), 5.39(\mathrm{~s}, 1 \mathrm{H}), 3.49(\mathrm{~d}, J=5.6 \mathrm{~Hz}, 2 \mathrm{H}), 3.43(\mathrm{t}, J=6.7 \mathrm{~Hz}, 2 \mathrm{H})$, 
$2.66(\mathrm{ddd}, J=40.4,25.6,22.0 \mathrm{~Hz}, 3 \mathrm{H}), 2.40-1.97(\mathrm{~m}, 2 \mathrm{H}), 1.95-1.85(\mathrm{~m}, 2 \mathrm{H})$. ESILRMS calcd. for $\mathrm{C} 23 \mathrm{H} 23 \mathrm{~N} 5 \mathrm{O} 4(\mathrm{M}+\mathrm{H})$ 434, found 434.<smiles>NCCCNC(=O)c1ccc(Oc2ccc(N)cc2)cc1</smiles>

\section{4-(4-aminophenoxy)-N-(3-azidopropyl)benzamide (19):}

A 2-5 mL process vial flushed with argon was charged with a solution of 4-(4-aminophenoxy) benzoic acid $(73.5 \mathrm{mg}, 0.32 \mathrm{mmol})$, EDC (67 mg, $0.35 \mathrm{mmol})$ and DMAP (60.4 mg, $0.35 \mathrm{mmol})$ in dry DMF (3 mL). Subsequently 3-azidopropylamine $(64 \mathrm{mg}, 0.64 \mathrm{mmol})$ and TEA $(0.09 \mathrm{~mL}, 0.64 \mathrm{mmol})$ were also added to the solution. The vial was sealed, placed into the cavity of the microwave reactor and irradiated at $120^{\circ} \mathrm{C}$ for $0.5 \mathrm{~h}$. The DMF was removed in vacuo and the resulting oil was extracted with $\mathrm{DCM} / \mathrm{H}_{2} \mathrm{O} \quad\left(\begin{array}{llll}3 & \mathrm{x} & 15 & \mathrm{~mL}\end{array}\right)$. Flash column chromatography was used for purification (EtOAc/Hexanes 4.5:5.5) to yield a brown solid (19) (31 mg, 31\%). ${ }^{1} \mathrm{H}$ NMR (400 MHz, $\left.\mathrm{CDCl}_{3}\right) \delta$ $7.98(\mathrm{~d}, J=7.8 \mathrm{~Hz}, 2 \mathrm{H}), 6.89-6.74(\mathrm{~m}, 4 \mathrm{H}), 6.66-6.56(\mathrm{~m}, 2 \mathrm{H}), 3.21-3.15(\mathrm{~m}, 2 \mathrm{H}), 3.13-3.06(\mathrm{~m}$,

2H), $1.79(\mathrm{dt}, J=12.8,6.3 \mathrm{~Hz}, 2 \mathrm{H}) .{ }^{13} \mathrm{C} \mathrm{NMR}\left(101 \mathrm{MHz}, \mathrm{CDCl}_{3}\right) \delta 128.60,121.59,116.43,116.24$, 49.61, 37.76, 28.78. ESILRMS calcd. for $\mathrm{C}_{16} \mathrm{H}_{17} \mathrm{~N}_{5} \mathrm{O}_{2}(\mathrm{M}+\mathrm{H})$ 312, found 312 .<smiles>COC1=CC(=O)CC(C(=O)Nc2ccc(Oc3ccc(C(=O)NCCCN)cc3)cc2)C1</smiles>

N-(3-azidopropyl)-4-(4-(3-methoxy-5-oxocyclohex-3-enecarboxamido)phenoxy)benzamide (20): A 2-5 mL process vial flushed with argon was charged with a solution of 3-methoxy-5-oxocyclohex-3enecarboxylic acid (19 mg, $0.11 \mathrm{mmol}), \mathrm{EDC}(21 \mathrm{mg}, 0.11 \mathrm{mmol})$ and DMAP (19 $\mathrm{mg}, 0.11 \mathrm{mmol})$ in dry DMF (3 mL). Subsequently 4-(4-aminophenoxy)-N-(3-azidopropyl)benzamide (19) (31 mg, 0.1 
mmol) and TEA $(0.01 \mathrm{~mL}, 0.1 \mathrm{mmol})$ in dry DMF $(2 \mathrm{~mL})$ were also added to the solution. The vial was sealed, placed into the cavity of the microwave reactor and irradiated at $120{ }^{\circ} \mathrm{C}$ for $0.5 \mathrm{~h}$. The DMF was removed in vacuo and the resulting oil was extracted with $\mathrm{DCM} / \mathrm{H}_{2} \mathrm{O}(3 \times 15 \mathrm{~mL})$. The organic phases were combined, dried over $\mathrm{Na}_{2} \mathrm{SO}_{4}$, filtered, and concentrated. Flash column chromatography was used for purification (EtOAc/Hexanes 1:1 to 8:2) to yield a yellow solid (20) (10 mg, 22\%) ${ }^{1} \mathrm{H}$ NMR (400 MHz, $\left.\mathrm{CDCl}_{3}\right) \delta 8.19(\mathrm{~s}, 1 \mathrm{H}), 7.68(\mathrm{t}, J=10.9 \mathrm{~Hz}, 2 \mathrm{H}), 6.90(\mathrm{dd}, J=19.4,8.4$ $\mathrm{Hz}, 4 \mathrm{H}), 6.72-6.57(\mathrm{~m}, 2 \mathrm{H}), 6.33(\mathrm{~s}, 1 \mathrm{H}), 5.39(\mathrm{~s}, 1 \mathrm{H}), 3.70(\mathrm{t}, J=12.3 \mathrm{~Hz}, 3 \mathrm{H}), 3.52(\mathrm{dt}, J=18.2$, $9.0 \mathrm{~Hz}, 2 \mathrm{H}), 3.45-3.42(\mathrm{~m}, 2 \mathrm{H}), 3.04(\mathrm{~s}, 1 \mathrm{H}), 2.79-2.45(\mathrm{~m}, 2 \mathrm{H}), 1.93-1.85(\mathrm{~m}, 2 \mathrm{H}), 1.85-1.74(\mathrm{~m}$, 2H). ${ }^{13} \mathrm{C} \mathrm{NMR}\left(100 \mathrm{MHz}, \mathrm{CDCl}_{3}\right) \delta 128.75,121.76,120.50,117.40,109.99,101.84,56.08,49.57$, 49.28, 41.63, 39.62, 37.85, 35.84, 31.34, 28.74. ESILRMS calcd. for C24H25N5O5 (M + H) 464, found 464.<smiles>N#CCCNC(=O)c1ccc(Oc2ccc(NC(=O)C3CC(=O)CC(=O)C3)cc2)cc1</smiles>

\section{N-(3-azidopropyl)-4-(4-(3,5-dioxocyclohex-3-enecarboxamido)phenoxy)benzamide (7):}

N-(3-azidopropyl)-4-(4-(3-methoxy-5-oxocyclohex-3-enecarboxamido)phenoxy)benzamide (20) (10 $\mathrm{mg}, 0.022 \mathrm{mmol})$ was added to a solution of $\mathrm{ACN} / \mathrm{H}_{2} \mathrm{O}(1: 1 \mathrm{v} / \mathrm{v}, 10 \mathrm{~mL})$ with $10 \mathrm{~mol} \% \mathrm{CAN}(1.2 \mathrm{mg}$, $0.002 \mathrm{mmol}$ ) and refluxed at $95^{\circ} \mathrm{C}$ for $3 \mathrm{~h}$. The reaction was cooled and concentrated. Flash column chromatography was used for purification (EtOAc to EtOAc/MeOH 9:1) to yield a white solid (7) (8 mg, 81\%) ${ }^{1} \mathrm{H}$ NMR (400 MHz, DMSO-d 6$) \delta 8.21(\mathrm{~d}, J=6.9 \mathrm{~Hz}, 2 \mathrm{H}), 7.51-7.42(\mathrm{~m}, 2 \mathrm{H}), 7.12(\mathrm{dt}, J$ $=10.8,5.4 \mathrm{~Hz}, 2 \mathrm{H}), 6.96(\mathrm{~d}, J=7.3 \mathrm{~Hz}, 2 \mathrm{H}), 5.25(\mathrm{~s}, 1 \mathrm{H}), 3.46(\mathrm{~s}, 2 \mathrm{H}), 3.33(\mathrm{~s}, 2 \mathrm{H}), 3.00-2.82(\mathrm{~m}$, 3H), $1.83-1.77(\mathrm{~m}, 2 \mathrm{H}) .{ }^{13} \mathrm{C}$ NMR $\left(100 \mathrm{MHz}, \mathrm{DMSO}-\mathrm{d}_{6}\right) \delta 128.51,125.90,60.20,49.02,46.15$, 40.50, 40.29, 40.08, 21.19, 14.51, 9.04. ESILRMS calcd. for $\mathrm{C}_{23} \mathrm{H}_{23} \mathrm{~N}_{5} \mathrm{O}_{5}(\mathrm{M}+\mathrm{H})$ 450, found 450 . 


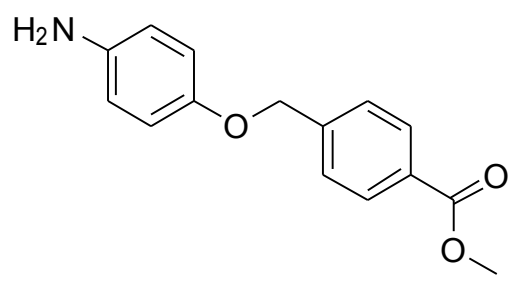

\section{Methyl 4-((4-aminophenoxy)methyl)benzoate (21):}

In an oven-dried round bottom flask flushed with argon $\mathrm{NaH}(60 \%$ suspension $60 \mathrm{mg}, 1.5 \mathrm{mM})$ was added to 4-aminophenol $(163.5 \mathrm{mg}, 1.5 \mathrm{mmol})$ in dry DMF $(5 \mathrm{~mL})$ and stirred for $1 \mathrm{~h}$ at $0{ }^{\circ} \mathrm{C}$. Methyl 4-(bromomethyl)benzoate $(230 \mathrm{mg}, 0.13 \mathrm{mmol})$ in dry DMF $(5 \mathrm{~mL})$ was slowly added to the solution. The reaction stirred for $2 \mathrm{~h}$. The DMF was removed in vacuo and the resulting oil was extracted with DCM $/ 10 \%$ sodium bicarbonate $(3 \times 15 \mathrm{~mL})$. The organic phases were combined, dried over $\mathrm{Na}_{2} \mathrm{SO}_{4}$, filtered, and concentrated. Flash column chromatography was used for purification (EtOAc/Hexanes 1:1 to EtOAc) to yield a white solid (21) $(265 \mathrm{mg}, 62 \%) .{ }^{1} \mathrm{H}$ NMR $\left(400 \mathrm{MHz}, \mathrm{CDCl}_{3}\right) \delta 8.06(\mathrm{t}, J=$ 14.1 Hz, 2H), 7.47 (t, $J=10.1 \mathrm{~Hz}, 2 \mathrm{H}), 6.84-6.77(\mathrm{~m}, 2 \mathrm{H}), 6.67-6.59(\mathrm{~m}, 2 \mathrm{H}), 5.07$ (d, $J=19.9 \mathrm{~Hz}$, 2H), 3.91 (s, 3H), 3.25 (s, 2H). ${ }^{13} \mathrm{C}$ NMR (100 MHz, $\left.\mathrm{CDCl}_{3}\right) \delta 166.86,151.58,142.78,140.45,129.77$, 129.46, 126.94, 116.32, 116.04, 70.10, 52.08. ESILRMS calcd. for $\mathrm{C}_{15} \mathrm{H}_{15} \mathrm{NO}_{3}(\mathrm{M}+\mathrm{H}) 258$, found 258.

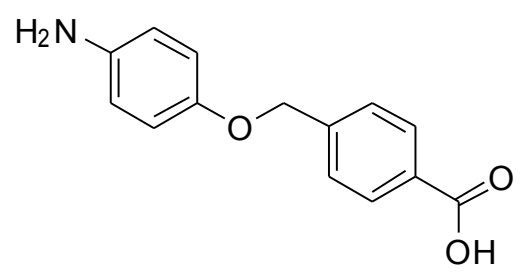

\section{4-((4-aminophenoxy)methyl)benzoic acid (22):}

In a round bottom flask at $0{ }^{\circ} \mathrm{C}$, potassium tert-butoxide $(1.06 \mathrm{~g}, 11 \mathrm{mM})$ was stirred in $50 \mathrm{~mL}$ of ether for $15 \mathrm{~min}$. $\mathrm{H}_{2} \mathrm{O}(0.05 \mathrm{~mL}, 2.76 \mathrm{mmol})$ was then added to the slurry. After 5 min methyl 4-((4aminophenoxy)methyl)benzoate (21) (265 $\mathrm{mg}, 0.92 \mathrm{mmol}$ ) was added and the reaction was stirred for 
$48 \mathrm{~h}$. The ether was removed in vacuo and flash column chromatography was used for purification (EtOAc/MeOH 9:1) to yield a yellow solid (22) (192 mg, 86\%). ${ }^{1} \mathrm{H}$ NMR (400 MHz, CD 3 OD) 7.97 (t, $J=10.0 \mathrm{~Hz}, 2 \mathrm{H}), 7.46(\mathrm{~d}, J=8.4 \mathrm{~Hz}, 2 \mathrm{H}), 6.87-6.73(\mathrm{~m}, 2 \mathrm{H}), 6.71(\mathrm{dd}, J=6.6,2.3 \mathrm{~Hz}, 2 \mathrm{H}) .{ }^{13} \mathrm{C}$ NMR (100 MHz, CD 3 OD) $\delta 152.10,141.74,140.05,129.22,126.53,116.83,115.57,110.12,69.79$. ESILRMS calcd. for $\mathrm{C}_{13} \mathrm{H}_{13} \mathrm{NO}_{3}(\mathrm{M}+\mathrm{H}) 244$, found 244 .

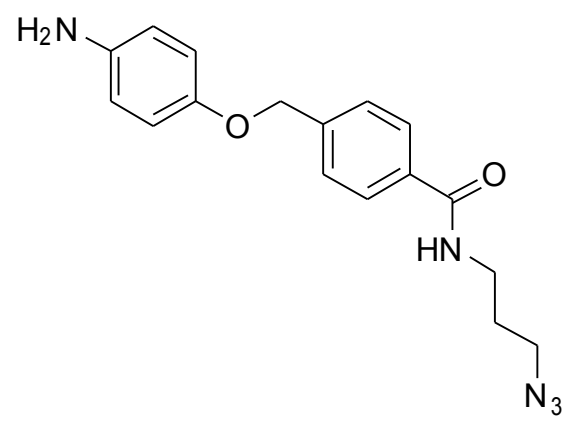

\section{4-((4-aminophenoxy)methyl)-N-(3-azidopropyl)benzamide (23):}

A 2-5 $\mathrm{mL}$ process vial flushed with argon was charged with a solution of 4-((4aminophenoxy)methyl)benzoic acid (22) (100 mg, $0.41 \mathrm{mmol})$, EDC (86 mg, $0.45 \mathrm{mmol})$ and DMAP (60.4 mg, $0.45 \mathrm{mmol})$ in dry DMF (3 mL). Subsequently 3-azidopropylamine (45 mg, $0.45 \mathrm{mmol})$ and TEA $(0.06 \mathrm{~mL}, 0.45 \mathrm{mmol})$ were also added to the solution. The vial was sealed, placed into the cavity of the microwave reactor and irradiated at $120{ }^{\circ} \mathrm{C}$ for $0.5 \mathrm{~h}$. The DMF was removed in vacuo and the resulting oil was extracted with $\mathrm{DCM} / 10 \%$ sodium bicarbonate $(3 \times 15 \mathrm{~mL})$. The organic phases were combined, dried over $\mathrm{Na}_{2} \mathrm{SO}_{4}$, and concentrated. Flash column chromatography was used for purification (EtOAc/Hexanes 7:3) to yield a brown solid (23) $(34 \mathrm{mg}, 48 \%) .{ }^{1} \mathrm{H}$ NMR (400 $\mathrm{MHz}$, $\left.\mathrm{CDCl}_{3}\right) \delta 8.25-8.13(\mathrm{~m}, 2 \mathrm{H}), 6.81-6.72(\mathrm{~m}, 2 \mathrm{H}), 6.66-6.58(\mathrm{~m}, 2 \mathrm{H}), 6.54(\mathrm{dd}, J=5.4,1.5 \mathrm{~Hz}, 2 \mathrm{H})$, $5.00(\mathrm{~s}, 2 \mathrm{H}), 3.75(\mathrm{dd}, J=9.3,4.5 \mathrm{~Hz}, 2 \mathrm{H}), 3.28(\mathrm{dd}, J=7.0,4.4,1.7 \mathrm{~Hz}, 2 \mathrm{H}), 1.84-1.74(\mathrm{~m}, 2 \mathrm{H})$. ${ }^{13} \mathrm{C}$ NMR $\left(100 \mathrm{MHz}, \mathrm{CDCl}_{3}\right) \delta 161.22,140.77,140.05,127.25,126.99,116.31,116.07,70.11,49.26$, 35.85, 34.91, 29.67, 28.67, 14.88. ESILRMS calcd. for $\mathrm{C}_{17} \mathrm{H}_{19} \mathrm{~N}_{5} \mathrm{O}_{2}(\mathrm{M}+\mathrm{H})$ 326, found 326 . 
<smiles>COC1=CC(=O)CC(C(=O)Nc2ccc(OCc3ccc(C(=O)NCCCN)cc3)cc2)C1</smiles>

\section{N-(3-azidopropyl)-4-((4-(3-methoxy-5-oxocyclohex-3- enecarboxamido)phenoxy)methyl)benzamide (24):}

A 2-5 mL process vial flushed with argon was charged with a solution of 3-methoxy-5-oxocyclohex-3enecarboxylic acid (17 mg, $0.10 \mathrm{mmol})$, EDC (19 mg, $0.1 \mathrm{mmol})$ and DMAP (17 mg, $0.1 \mathrm{mmol})$ in dry DMF (3 mL). Subsequently 4-((4-aminophenoxy)methyl)-N-(3-azidopropyl)benzamide (23) (34mg, $0.09 \mathrm{mmol})$ and TEA $(0.01 \mathrm{~mL}, 0.1 \mathrm{mmol})$ in dry DMF $(2 \mathrm{~mL})$ were also added to the solution. The vial was sealed, placed into the cavity of the microwave reactor and irradiated at $120^{\circ} \mathrm{C}$ for $0.5 \mathrm{~h}$. The DMF was removed in vacuo and the resulting oil was extracted with $\mathrm{DCM} / \mathrm{H}_{2} \mathrm{O}(3 \times 15 \mathrm{~mL})$. The organic phases were combined, dried over $\mathrm{Na}_{2} \mathrm{SO}_{4}$, filtered, and concentrated. Flash column chromatography was used for purification (EtOAc/Hexanes 7:3 to EtOAc) to yield a yellow solid (24) (12.8 mg, 30\%). ${ }^{1} \mathrm{H}$ NMR (400 MHz, $\left.\mathrm{CDCl}_{3}\right) \delta 7.72-7.67(\mathrm{~m}, 2 \mathrm{H}), 7.44(\mathrm{dd}, J=14.9,8.5 \mathrm{~Hz}, 2 \mathrm{H})$, $6.98-6.90(\mathrm{~m}, 2 \mathrm{H}), 6.85(\mathrm{~d}, J=2.2 \mathrm{~Hz}, 1 \mathrm{H}), 5.29-5.25(\mathrm{~m}, 1 \mathrm{H}), 5.05(\mathrm{~s}, 2 \mathrm{H}), 3.85(\mathrm{~s}, 1 \mathrm{H}), 3.50(\mathrm{~d}, J$ $=6.0 \mathrm{~Hz}, 2 \mathrm{H}), 3.39(\mathrm{t}, J=6.5 \mathrm{~Hz}, 2 \mathrm{H}), 2.73-2.44(\mathrm{~m}, 3 \mathrm{H}), 1.89-1.82(\mathrm{~m}, 2 \mathrm{H})$. ESILRMS calcd. for $\mathrm{C}_{25} \mathrm{H}_{27} \mathrm{~N}_{5} \mathrm{O}_{5}(\mathrm{M}+\mathrm{Na}) 500.1$, found 500.2. 
<smiles>N#CCCNC(=O)c1ccc(COc2ccc(NC(=O)C3CC(=O)CC(=O)C3)cc2)cc1</smiles>

N-(3-azidopropyl)-4-((4-(3,5-dioxocyclohexanecarboxamido)phenoxy)methyl)benzamide (8):

N-(3-azidopropyl)-4-((4-(3-methoxy-5-oxocyclohex-3-enecarboxamido)phenoxy)methyl)benzamide

(24) $(15 \mathrm{mg}, 0.03 \mathrm{mmol})$ was added to a solution of $\mathrm{ACN} / \mathrm{H}_{2} \mathrm{O}(1: 1 \mathrm{v} / \mathrm{v}, 10 \mathrm{~mL})$ with $10 \% \mathrm{CAN}(1.6$ $\mathrm{mg}, 0.003 \mathrm{mmol}$ ) and refluxed at $95^{\circ} \mathrm{C}$ for $3 \mathrm{~h}$. The reaction was cooled and concentrated. Flash column chromatography was used for purification (EtOAc to EtOAc/MeOH 9:1) to yield a white solid (8) $(11.8 \mathrm{mg}, 85 \%){ }^{1} \mathrm{H} \mathrm{NMR}\left(400 \mathrm{MHz}, \mathrm{CD}_{3} \mathrm{OD}\right) \delta 7.81(\mathrm{~s}, 2 \mathrm{H}), 7.61(\mathrm{~s}, 2 \mathrm{H}), 7.03(\mathrm{~s}, 4 \mathrm{H}), 5.12(\mathrm{~s}$, 2H), $3.65(\mathrm{~s}, 2 \mathrm{H}), 3.41(\mathrm{~s}, 2 \mathrm{H}), 2.88(\mathrm{~s}, 2 \mathrm{H}), 2.75-2.55(\mathrm{~m}, 2 \mathrm{H}), 1.87(\mathrm{~s}, 2 \mathrm{H})$. ESILRMS calcd. for $\mathrm{C}_{24} \mathrm{H}_{25} \mathrm{~N}_{5} \mathrm{O}_{5}(\mathrm{M}+\mathrm{H}) 464$, found 464.

General procedure for PTP activity assay. Steady-state phosphatase assays were performed by following the enzymatic turnover of 4-methylumbelliferyl phosphate (4-MUP) by the protein tyrosine phosphatase YopH or PTP1b. ${ }^{[3]}$ Briefly, to $30 \mu \mathrm{L}$ of YopH or PTP1b (35 nM) in buffer (32 mM HEPES pH 7.2, $5 \mathrm{mM} \mathrm{NaCl}, 2.5 \mathrm{mM}$ EDTA, 0.83\% glycerol, 0.002\% Brij-35) was added $5 \mu \mathrm{L}$ of the azido-probe or DMSO control and incubated for $15 \mathrm{~min}$. The assay was initiated by addition of $20 \mu \mathrm{L}$ of 4-MUP $(500 \mu \mathrm{M})$. The fluorescence owing to dephosphorylation of 4-MUP was measured over 15 min at $25{ }^{\circ} \mathrm{C}$ using a SpectraMax M5 plate reader (Costar 94-well plate, $\lambda_{\mathrm{ex}}=358 \mathrm{~nm}, 449 \mathrm{~nm}$ emission filter). To evaluate compounds for aggregation-based inhibition, experiments were performed as described above except that $0.02 \%$ Triton-X100 was included in the assay buffer.

LC/MS analysis of dimedone-tagged YopH. YopH $(3 \mu \mathrm{M})$ was incubated with dimedone $(10 \mathrm{mM})$ 
and $\mathrm{H}_{2} \mathrm{O}_{2}(30 \mu \mathrm{M})$ or DMSO alone in buffer (32 mM HEPES pH 7.2, $5 \mathrm{mM} \mathrm{NaCl}, 2.5 \mathrm{mM}$ EDTA, 0.83\% glycerol, $0.002 \%$ Brij-35, $0.02 \%$ Triton X-100) with rocking for $6 \mathrm{~h}$ at $\mathrm{RT}$. The resulting samples were concentrated and exchanged into $0.1 \%$ formic acid using Amicon Ultra Centrifugal Filters (Amicon Ultra, $0.5 \mathrm{~mL}, 10 \mathrm{k} \mathrm{MWCO}$ ). The concentrated samples were then subjected MS analysis. An Agilent Eclipse XDB-C8 2.1mm x 15mm trap with mobile phases A (0.1\% formic acid in water $)$ and $\mathrm{B}(0.1 \%$ formic acid in acetonitrile) was used to trap, desalt and elute proteins by a linear gradient $5-90 \%$ of mobile phase B over 7 minutes at a flow rate of $200 \mathrm{uL} / \mathrm{min}$. The desalted proteins were eluted directly on to an electrospray linear ion trap mass spectrometer (LTQ XL, Thermo Scientific) to measure protein mass.

Determination of the dissociation constant for inhibitor binding $\left(K_{\mathrm{i}}\right)$. In the absence of oxidant, dimedone-based probes function as reversible inhibitors. The compound-dependence of PTP inhibition was fit to a simple model of competitive inhibition (eq 1) to yield apparent inhibitor binding constants $\left(K_{\mathrm{i}}\right)$ :

$$
\frac{v}{[\mathrm{YopH}]}=\frac{k_{\mathrm{cat}}[\mathrm{S}]}{\left(K_{\mathrm{m}}+[\mathrm{S}]\right)\left(1+[\mathrm{I}] / K_{\mathrm{i}}\right)}
$$

where $[\mathrm{I}]$ is the inhibitor concentration, $[\mathrm{S}]$ is the substrate (4-MUP) in excess, and $K_{\mathrm{i}}$ is the apparent inhibitor binding constant.

Detecting reversible PTP oxidation with azido-probes. YopH sulfenic acid was generated by oxidizing protein $(30 \mu \mathrm{M})$ with 100 eq $\mathrm{H}_{2} \mathrm{O}_{2}$ for $1 \mathrm{~h}$ at RT in buffer (32 mM HEPES pH 7.2, $5 \mathrm{mM}$ $\mathrm{NaCl}, 2.5 \mathrm{mM}$ EDTA, 0.83\% glycerol, 0.002\% Brij-35, 0.02\% Triton-X100). Following oxidation, 
catalase (100 units) was added for 15 min at RT to remove excess $\mathrm{H}_{2} \mathrm{O}_{2}$. Sulfenic acid modification of YopH was monitored by incubating protein $(3 \mu \mathrm{M})$ with azido-probes 2 -8 $(0.5 \mathrm{mM})$ or DMSO $(5 \%$ $\mathrm{v} / \mathrm{v})$ for $15 \mathrm{~min}$ at RT. In some reactions, YopH $(30 \mu \mathrm{M})$ was pretreated with dimedone $(50 \mathrm{mM})$ or TCEP $(0.9 \mathrm{mM})$ for $0.5 \mathrm{~h}$ at RT and then incubated with the azido-probe. In subsequent steps, azidetagged YopH was conjugated to phosphine-activated biotin (p-biotin; $200 \mu \mathrm{M}$ ) via the Staudinger ligation for $2 \mathrm{~h}$ at RT. ${ }^{[4]}$ To detect PTP1B oxidation, the phosphatase was treated with $\mathrm{H}_{2} \mathrm{O}_{2}$ and probed with 2, 5, 6 or DMSO (5\% v/v) in buffer (50 mM HEPES pH 7.2, $1 \mathrm{mM}$ EDTA, 0.05\% NP-40), as described above.

Probing sulfenic acid modification of GAPDH. Oxidized GAPDH $(15 \mu \mathrm{M})$ in buffer $(32 \mathrm{mM}$ HEPES pH 7.2, 5 mM NaCl, 2.5 mM EDTA, 0.83\% glycerol, 0.002\% Brij-35, 0.02\% Triton-X100) was incubated with DAz-1 $(0.5 \mathrm{mM})$, compound 5 or $6(0.5 \mathrm{mM})$ or DMSO $(5 \% \mathrm{v} / \mathrm{v})$ for $0.5 \mathrm{~h}$ at 37 ${ }^{\circ} \mathrm{C}$. Staudinger ligation was carried out by incubation of purified protein with p-biotin $(200 \mu \mathrm{M})$ for 2 h at $37^{\circ} \mathrm{C}$.

Western blot. Biotinylated proteins were separated by SDS-PAGE using Criterion XT 4-20\% BisTris gels (BioRad) and transferred to a polyvinylidene difluoride (PVDF) membrane (BioRad). After transfer, the PVDF membrane was blocked with 3\% BSA in phosphate-buffered saline Tween-20 (PBST) for $1 \mathrm{~h}$ at RT. The membrane was washed with PBST $(2 \times 10 \mathrm{~min})$ and then incubated with HRP-streptavidin (1:5,000 to 1:50,000; Pierce). PVDF membrane was washed with PBST $(2 \times 5$ min, $1 \times 10 \mathrm{~min}$ ) and then developed with ECL Plus chemiluminescence (GE Healthcare). GAPDH was probed with anti-GAPDH (1:1,000; Santa-Cruz) and rabbit anti-mouse-HRP (1:35,000; Invitrogen). The quality of protein transfer and loading was ascertained by staining the PVDF membrane with Ponceau S. 
Computational method for Autodock calculations: Coordinates for compounds were built with ideal geometry in InsightII (Accelrys, Inc.), including coordinates for the $\mathrm{C} \beta$ and $\mathrm{S} \gamma$ positions of the cysteine adduct. The C $\beta$ position was then overlapped on CYS403 in PDB entry 3blt. Autodock ${ }^{[5]}$ was $^{2}$ used to perform a simulated annealing conformation search, keeping the $\mathrm{C} \beta$ atom at the crystallographic position and searching through rotational and torsional degrees of freedom. Initial simulations revealed that the cyclic diketone formed close contacts with amino acids surrounding the active site, giving highly unfavorable interaction energies for all conformations. We then modeled induced fit by calculating a smoothed energy function. Smoothing is performed by calculating the energy potential, then scanning through the potential with a moving window, taking the minimum energy within the window at each point. This has the effect of widening the favorable basins in the potential. The default width for this smoothing window in AutoDock is $0.5 \AA$. In the current study, we increased this to $1.5 \AA$ for atoms in the cyclic diketone, and kept the default values for the variable portions of the compounds.

\section{References Cited}

[1] K. G. Reddie, Y. H. Seo, W. B. Muse III, S. E. Leonard, K. S. Carroll, Mol. Biosys. 2008, 4, 521.

[2] Z. Y. Zhang, J. C. Clemens, H. L. Schubert, J. A. Stuckey, M. W. Fischer, D. M. Hume, M. A. Saper, J. E. Dixon, J. Biol. Chem. 1992, 267, 23759.

[3] S. B. Hong, T. H. Lubben, C. M. Dolliver, A. J. Petrolonis, R. A. Roy, Z. Li, T. F. Parsons, P. Li, H. Xu, R. M. Reilly, J. M. Trevillyan, A. J. Nichols, P. J. Tummino, T. G. Gant, Bioorg. Chem. 2005, 33, 34.

[4] E. Saxon, C. R. Bertozzi, Science 2000, 287, 2007.

[5] G. M. Morris, R. Huey, W. Lindstrom, M. F. Sanner, R. K. Belew, D. S. Goodsell, A. J. Olson, J. Comput. Chem. 2009, 30, 2785-2791. 
a)

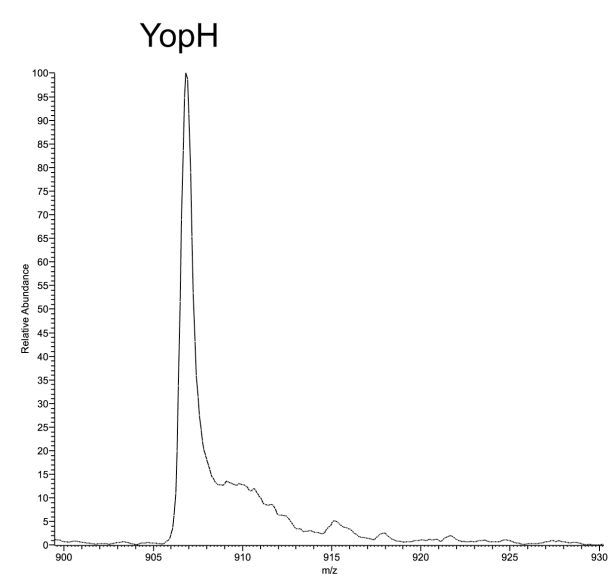

b)

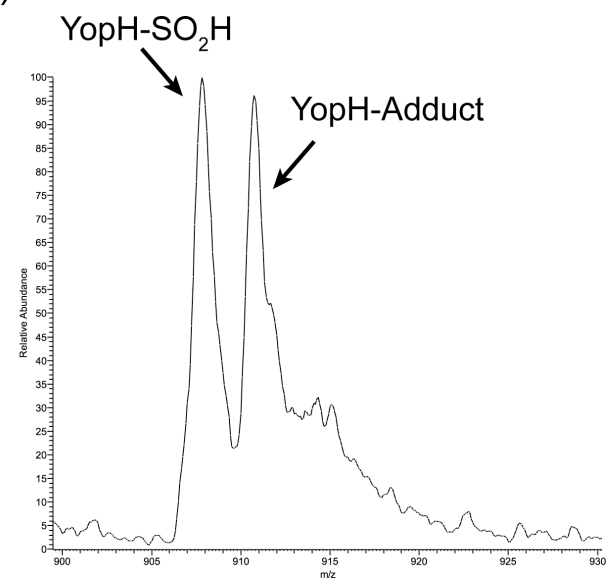

Figure S1. YopH forms a covalent adduct with dimedone with 1:1 stoichiometry. a) ESI mass spectra of active, unmodified YopH (33514.8 Da expected; 33514.6 Da observed). b) ESI mass spectrum of $\mathrm{H}_{2} \mathrm{O}_{2}$-treated YopH incubated with dimedone (33653.6 Da expected; 33653.2 Da observed). The signal at $\sim 908 \mathrm{~m} / z$ corresponds to sulfinic acid-modified YopH (33546.8 expected; 33549.7 Da observed). 


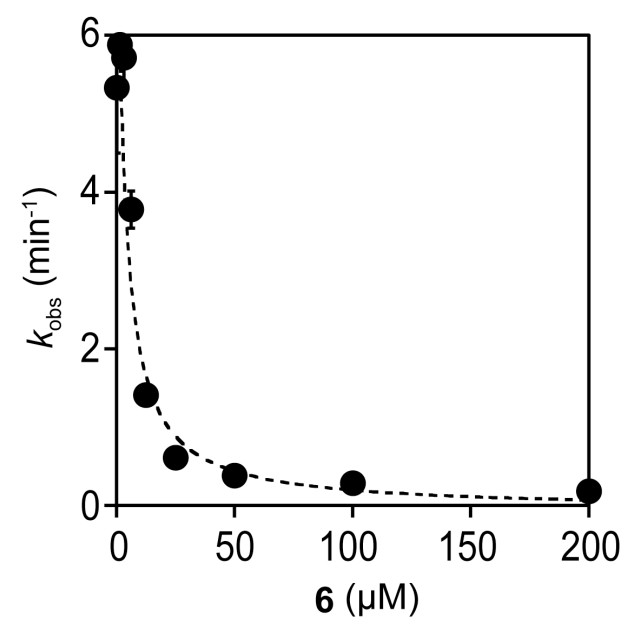

Figure S2. Plot of averaged initial rate versus compound 6 used to determine the averaged $K_{\mathrm{i}}$ for the inhibitor ( $n=3$, error bars show the standard deviation). Dashed line represents fit to a simple model for competitive inhibition $\mathrm{R}^{2} \geq 98 \%$. 


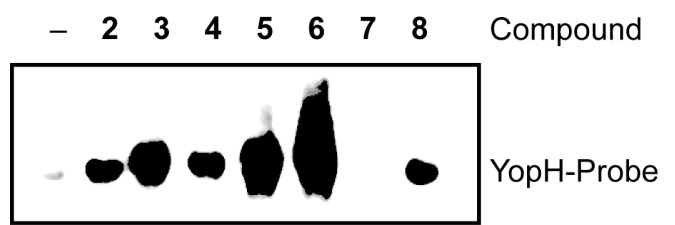

Strep-HRP

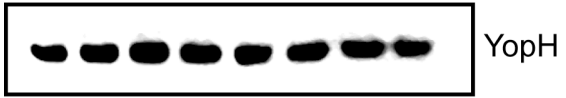

Ponceau S

Figure S3. Detecting sulfenic acid modification of YopH. The phosphatase was oxidized with $\mathrm{H}_{2} \mathrm{O}_{2}$, incubated with compounds $\mathbf{2 - 8}$ or DMSO alone (-) and analyzed by streptavidin-HRP western blot as described above. Figure S3 represents a longer exposure of the autoradiographic film from Figure 4a in the main text. 


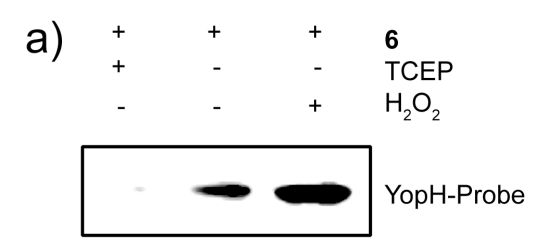

Strep-HRP

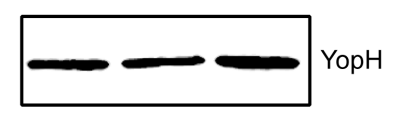

Ponceau S b)

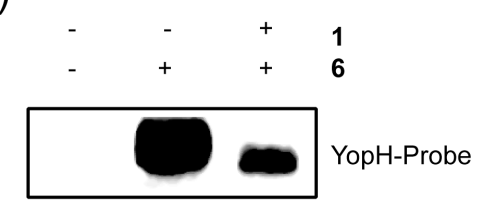

Strep-HRP

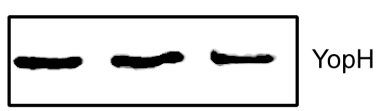

Ponceau S

Figure S4. Compound 6 selectively modifies sulfenic acid-modified YopH. a) YopH labeling by compound 6 requires oxidation by $\mathrm{H}_{2} \mathrm{O}_{2}$. YopH was treated with the reducing agent TCEP, buffer alone, or $\mathrm{H}_{2} \mathrm{O}_{2}$ and then incubated with compound 6. Following Staudinger ligation, covalent modification of YopH by $\mathbf{6}$ was determined by streptavidin-HRP western blot. b) Dimedone pretreatment blocks YopH modification by compound 6. YopH was treated with DMSO alone, compound 6, or pre-treated with dimedone $\mathbf{1}$ and then incubated with 6, as described above. Following Staudinger ligation, covalent modification of YopH by $\mathbf{6}$ was determined by streptavidin-HRP western blot. 


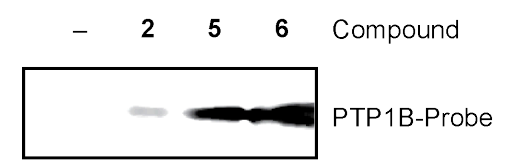

Strep-HRP

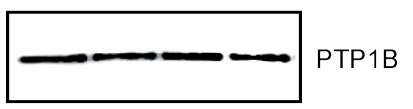

Ponceau S

$21565 \quad 100 \quad$ Relative Intensity (\%)

Figure S5. Analysis of RBP selectivity for oxidized PTP1B. a) RBP 5 and $\mathbf{6}$ detect sulfenic acid in oxidized PTP1B with increased sensitivity over the parent compound DAz-1 2. PTP1B was oxidized with $\mathrm{H}_{2} \mathrm{O}_{2}$ and incubated with compounds 2, 5, 6 or DMSO (-) alone. Following p-biotin conjugation, reactions were analyzed by streptavidin-HRP western blot (top). Equal loading was verified by Ponceau S staining (bottom). 